\title{
The contemporary role and potential of pharmacist contribution for community health using social media
}

\author{
${ }^{1}$ Pharmacy Practice, Airlangga University Faculty of Pharmacy, Surabaya, Indonesia, E-mail: andi-h@ff.unair.ac.id. \\ https://orcid.org/0000-0002-9716-3126. \\ ${ }^{2}$ Management and Science University School of Pharmacy, Shah Alam, Malaysia \\ ${ }^{3}$ Communication Studies, Universitas Airlangga Fakultas Ilmu Sosial dan Ilmu Politik, Surabaya, Indonesia
}

\begin{abstract}
:
Background: Social media (SM) is everywhere, and it affects all aspects of life, including health care. This study aimed to identify pharmacist activity in SM and explore the potential for pharmacist contributions using SM. Methods: Focus group discussions (FGDs) were conducted in four cities in Indonesia. The investigators collaborated with a local pharmacist association to select a wide range of pharmacists as participants. The discussions were audiotaped, transcribed, and thematically analyzed.

Results: Forty-one pharmacists participated in the FGDs. Four broad themes were identified: pharmacist use of SM, current initiatives using SM, public acceptance, and opportunities for role expansion. WhatsApp was the most used SM and had meaningful contribution to spread information and change a patient's behavior. Participants used SM mainly for personal purposes, but when it came to pharmacy and health issues, they were among the first to be contacted by patients or to counter misleading information in SM. A number of participants actively used SM for health promotion in form of sharing health information, promoting use of medicines, providing drug reminders, and encouraging compliance to medication. The public had a high trust to information provided by pharmacists in SM. Although participants believed pharmacists can play a role in educating patients and influencing the health of the communities, they considered being active in SM as burdensome, time consuming, and potential for lawsuit.

Conclusions: SM has become a venue for pharmacists to improve the health of the people. Several unique features in SM may facilitate pharmacist contributions; however, whether pharmacists continue to undertake such initiative cannot be guaranteed.
\end{abstract}

Keywords: health care, pharmacist, social media

DOI: $10.1515 /$ jbcpp-2019-0329

Received: November 4, 2019; Accepted: November 6, 2019

\section{Introduction}

Whether you are a professor or a primary school student, from high-income countries (HICs) or low- and middle-income countries (LMICs), a gadget freak, or an amateur, people nowadays are familiar with and most of them - connected with social media (SM). Nearly half of the global population are active SM users, and the number keeps increasing [1]. Facebook, Instagram, Twitter, YouTube, and WhatsApp are among the top SM platforms that have gained popularity over the past decade. SM has broadly affected our lives, not only in the way we communicate with others but also in the way we live and work. Health care, particularly pharmacy practice, is also not immune from impact of SM.

A number of studies have reported the influence of SM to pharmacy. For example, pharmacists used WhatsApp to communicate with peers about their professional works and share best practice between junior and senior pharmacists [2]. The most popular photo sharing application - Instagram - has been used by pharmacists to share health-related images, including providing patient education and sharing the latest research in pharmacy [3]. Other popular SM platforms such as Facebook have long been used by pharmacists to communicate with patients and to facilitate discussion about medication management [4]. 
The use of SM by pharmacists, however, has sparked a number of concerns, such as privacy issues [5], confidentiality [6], and unprofessional misconduct by pharmacists during online activities [7]. In addition, pharmacists have been found to use SM primarily for personal [8] or social [9] purposes. For example, only $10 \%$ of Twitter accounts owned by pharmacists in the United States were used for tweeting professional issues, with the remaining accounts used for posting comments about social life [10]. Other studies reported that pharmacists were not very enthusiastic to use SM for professional matters [11].

It is without a doubt that SM provides opportunities and challenges for pharmacists to deliver better pharmacy services. The contribution of pharmacists to improve community health through SM seems to be promising. However, the evidence of pharmacist involvement and contributions using SM particularly in LMICs is limited. The growing popularity of SM in LMICs teamed up with technological advancements, e.g., high-speed Internet connection and increased Internet penetration, may have provided a venue for pharmacist online interaction [12]. Nevertheless, not much is known about pharmacists' activities and their roles in SM in the setting of LMICs. Therefore, this study aimed to identify pharmacist activity in SM and to explore potential role for pharmacist contributions using SM in Indonesia, representing one of the LMICs with the highest number of active SM users [13].

\section{Materials and methods}

\section{Study design and research approval}

To explore the objective of this study, qualitative focus group discussions (FGDs) were undertaken. FGDs were selected to enable understanding and to obtain more details about pharmacists' ideas, roles, and responses about SM. In addition, FGDs provide more opportunities to delve into pharmacists' activities using SM and how public perceived their online activities. Permission to conduct the research was obtained from the Board of Social and Political Studies (BAKESBANGPOL) of East Java and the Indonesian Pharmacist Association.

\section{Study setting and participant}

This study was conducted between July and September 2019 in four different cities in Java Island, Indonesia. Java Island was selected because it is the most populous island in Indonesia, comprising of multicultures, multilanguages, and a mix of low- to high-income people with Internet penetration, and SM users were the highest in Indonesia [14]. The four cities selected were Surabaya (the capital city of East Java Province, population 2.7 million people), Banyuwangi (the outer city of East Java province, population 1.6 million people), Semarang (the capital city of Central Java Province, population 1.5 million people), and Klaten (the outer city of Central Java, population 1.1 million) [15]. These cities represent a unique combination of metropolitan and suburban/traditional lifestyle, contrast in socioeconomic situations, and population heterogeneity.

Pharmacists were recruited as participants, using the purposive sampling technique. Potential participants were recommended by the local Indonesian Pharmacist Association and expanded with additional participants from the researcher's list of pharmacist SM influencers. Candidates were contacted by the investigator via phone or WhatsApp message. Candidates agreeing to participate were enrolled into a WhatsApp group specific for each FGD group - managed by the researcher. This is to maintain collective communication, including schedule and location for FGD. Candidates in each city were selected to represent a variety of age-group, gender, and work backgrounds. Each FGD was attended by 10-11 participants.

\section{Development of the interview guide}

Before the FGD, participants were required to complete an online questionnaire mainly asking about the type and name of SM account owned by the candidates, the number of friends/followers/subscribers in each SM account, and the time spent for online activities.

The topic guide for the FGD was derived from online survey findings and studies on SM communication for health professionals [9], [11], [16] and developed from the discussion among investigators focusing on the latest trend and phenomenon of SM use in the contemporary Indonesian health care [17], [18]. Key points of the topic guide including the use of SM by pharmacists (type of SM, their activities in SM, the rationale of using SM, factors influencing their online activities, and how they perceive the benefits of SM in general) and perceived contribution and roles using SM (innovation/action delivered using SM, evidence of effectiveness, allocation 
and proportion for professional-personal-social purposes, public acceptance toward pharmacist involvement in SM, and strategies for effective communication in SM).

\section{Conduct of the FGDs}

Four FGDs were conducted in Surabaya, Banyuwangi, Semarang, and Klaten, respectively. Each FGD was facilitated by the investigators of the study (AH and TPR). Both investigators were expert in the qualitative studies. One of the investigators represented pharmacy practice and the others represented communication science. Before the FGD, all participants were clearly informed about the aim and the mechanism of the FGD. In addition, they had to provide written consent before starting the discussion. The FGD was organized in four sessions: introduction, general use of SM by pharmacists, contribution-related activities using SM, and closing. The discussion was conducted in Indonesian language, and each FGD took approximately 90-100 min. All FGDs were audiotaped. All participants were offered a small token of appreciation and IDR 200,000 $( \pm$ US \$15) cash for travel costs.

\section{Data analysis}

All interviews were transcribed verbatim by a professional transcribing service. The transcripts were translated into English by one of the investigators and subsequently checked and verified by all investigators to ensure the quality of the transcripts. Thematic analysis was used in the analysis of the interviews. The analysis began with each investigator independently reviewing the transcripts and developing initial coding framework. The coding framework was collated into meaningful themes, and the process continued until all relevant information was completely analyzed. The results of this process were brought into investigators' meeting to resolve any discrepancies and to reach consensus regarding the final theme.

\section{Results}

Overall, 41 pharmacists participated in four FGDs. All participants were Indonesians, and majority of participants were female (Table 1). All respondents were active users in multiple SM platforms, and WhatsApp was the most commonly used SM (Table 2).

Table 1: Characteristics of the participants $(n=41)$.

\begin{tabular}{lr}
\hline Characteristics & No. of respondents, \% \\
\hline Gender & 10 \\
Male & 31 \\
Female & \\
Highest pharmacy-related education & 33 \\
Undergraduate + apothecary & 8 \\
Graduate + apothecary & 37 \\
Ethnicity & 1 \\
Javanese & 1 \\
Sundanese & 1 \\
Sasaknese & 1 \\
Balinese & \\
Chinese & 14 \\
Experience as pharmacist, years & 11 \\
$1-5$ years & 16 \\
$6-10$ years & \\
$>10$ years & \\
\hline
\end{tabular}


Table 2: Information about respondents' SM.

\begin{tabular}{|c|c|}
\hline Type of information & No. of responses $(\%)$ \\
\hline \multicolumn{2}{|l|}{ SM accounts $(n=41)^{\mathrm{a}}$} \\
\hline WhatsApp & $41(100)$ \\
\hline Facebook & $34(83)$ \\
\hline Instagram & $31(76)$ \\
\hline Twitter & $14(34)$ \\
\hline Telegram & $15(37)$ \\
\hline Line & $9(22)$ \\
\hline YouTube & $8(20)$ \\
\hline Blog & $4(10)$ \\
\hline \multicolumn{2}{|c|}{ Number of friends/followers/subscribers (people) } \\
\hline \multicolumn{2}{|c|}{ WhatsApp $(\mathrm{n}=36)$} \\
\hline $0-50$ & $20(55.56)$ \\
\hline $51-100$ & $2(5.56)$ \\
\hline $101-500$ & $10(27.78)$ \\
\hline $501-1000$ & $2(5.56)$ \\
\hline$>1000$ & $2(5.56)$ \\
\hline \multicolumn{2}{|l|}{ Facebook $(\mathrm{n}=34)$} \\
\hline $0-50$ & $2(5.88)$ \\
\hline $51-100$ & $3(8.82)$ \\
\hline $101-500$ & $10(29.41)$ \\
\hline $501-1000$ & $5(14.71)$ \\
\hline$>1000$ & $14(41.18)$ \\
\hline \multicolumn{2}{|l|}{ Instagram $(\mathrm{n}=31)$} \\
\hline $0-50$ & $4(12.9)$ \\
\hline $51-100$ & 5 (16.13) \\
\hline $101-500$ & $14(45.16)$ \\
\hline $501-1000$ & $5(16.13)$ \\
\hline$>1000$ & $3(9.68)$ \\
\hline \multicolumn{2}{|l|}{ Twitter $(\mathrm{n}=14)$} \\
\hline $0-50$ & $10(71.43)$ \\
\hline $51-100$ & $1(7.14)$ \\
\hline $101-500$ & $2(14.29)$ \\
\hline $501-1000$ & $1(7.14)$ \\
\hline$>1000$ & 0 \\
\hline \multicolumn{2}{|l|}{ Telegram $(n=15)$} \\
\hline $0-50$ & $11(73.3)$ \\
\hline $51-100$ & $1(6.67)$ \\
\hline $101-500$ & $1(6.67)$ \\
\hline $501-1000$ & 0 \\
\hline$>1000$ & $2(13.32)$ \\
\hline \multicolumn{2}{|l|}{ Line $(n=9)$} \\
\hline $0-50$ & $7(77.78)$ \\
\hline $51-100$ & $2(22.22)$ \\
\hline $101-500$ & 0 \\
\hline $501-1000$ & 0 \\
\hline$>1000$ & 0 \\
\hline \multicolumn{2}{|l|}{ YouTube $(\mathrm{n}=8)$} \\
\hline $0-50$ & $7(87.5)$ \\
\hline $51-100$ & $1(12.5)$ \\
\hline $101-500$ & 0 \\
\hline $501-1000$ & 0 \\
\hline$>1000$ & 0 \\
\hline \multicolumn{2}{|c|}{ Estimated time spent in SM per day $(n=41)$} \\
\hline$<1 \mathrm{~h}$ & $9(22)$ \\
\hline $1-3 \mathrm{~h}$ & $19(46)$ \\
\hline$>3 \mathrm{~h}$ & $13(32)$ \\
\hline
\end{tabular}

${ }^{a}$ Multiple answers were allowed. 


\section{Focus group findings}

Four broad themes were identified from the thematic analysis, namely, (1) pharmacist use of SM, (2) current initiatives using SM, (3) public acceptance, and (4) opportunities for role expansion. Table 3 provides illustrative quotes relevant to each theme.

Table 3: Illustrative quote representing FGD findings.

First theme: pharmacist
use of SM

"I have account on Facebook, Twitter, Instagram, but I often use WhatsApp for professional communication." (FGD participant in Surabaya - Female)

"I used to use Facebook (for photo sharing) but I am currently active on Instagram. I do share some important messages in Instagram such as (pharmaceutical) product information or official information from the Ministry of Health or BPOM (The Indonesian National Agency of Drug and Food Control), but I use Instagram mostly for sharing and storing interesting photos." (FGD participant in Klaten - Female) "I use Facebook to find old friends or classmates, Instagram for sharing photos and following popular persons (e.g., celebrities), YouTube just for fun and of course WhatsApp. I use WhatsApp for communicating with colleagues about job, we have a group for that." (FGD participant in Semarang - Male)

Second theme: current initiatives using SM "I often clarify misleading information about medicines, sharing health information, notify people about side effect (of medicines) via SM." (FGD participant in Banyuwangi - Female)

"We offer WhatsApp reminder to our customers. We generate message to remind particular patients for taking medicines." (FGD participant in Banyuwangi - Female) "I am active in Telegram as I am appointed as one of Master of Agent of Change (an initiative by Ministry of Health to recruit pharmacist influencers in SM). I am one of the admins of Gema Cermat (a national campaign by Ministry of Health to increase public awareness about medicines use) Telegram group which members have reached more than 10,000 people across Indonesia. We often share health information, discuss health problems with common people and frequently conduct online Telegram course (a session of online talk-show in which there is expert as facilitator and moderator to lead the discussion) about medicines and health." (FGD participant in Semarang - Male)

Third theme: public accep"Patients, friends and families know that I am pharmacist. They'll ask me first about tance pharmacy, tag me or send me private message." (FGD participant in Semarang - Female) "If there are any latest issues or news about health and medicines in any WhatsApp group that I joined - it can be old classmate or alumni (group), community and neighborhood (group), family (group) or (school), parents and carers (group), the member of the group often tag my name to seek my response." (FGD participant in Surabaya - Female)

"Patients are welcome to us (in SM). However, they sometime believe hoax information rather than trusting our advices. I have one patient died as she stopped her chemotherapy and changed into herbal medicine. I convinced her that it is not yet confirmed (the safety and efficacy of the herbal medicines) but she insisted to consume it after all." (FGD participant in Banyuwangi - Female)

Fourth theme: opportunities for role expansion "Pharmacist can do a lot more with SM, but that costs time and (sacrificing) privacy, not to mention lawsuit if you do it wrong." (FGD participant in Klaten - Male) "I often confront pharmacist colleagues or other professionals especially doctors in the WhatsApp group whenever they wrote something wrong about medication and diseases. But I don't do this if they are my seniors or respected ones. Sometimes I prefer to remind them individually." (FGD participant in Semarang - Female)

"I see potential role for pharmacist in SM, but it is not easy to create a good content with astonishing appearances with which people are willing to share and make it viral. I often check and re-check my message before sending (the message) but in the end I am not confident to share (the message)." (FGD participant in Banyuwangi - Female)

The first theme highlights that participants generally used SM for both professional and personal purposes. WhatsApp increasingly became the primary platform of SM and commonly used for communication. The feature of WhatsApp that allows for group communication enables participants to interact with many people at once. This would also allow them to discuss work issues with colleagues and to chat with patients in a professional manner. However, the main concept of SM is social networking. Therefore, it is not surprising that participants used SM mostly for social purposes. One participant claimed that she used Instagram for professional business, but she mostly used Instagram for photo sharing and collection. 
The second theme demonstrates that participants had a number of initiatives to use SM for promoting public health, increasing patient awareness about medication safety, and promoting pharmacy-related topics including pharmacy products and services. In fact, participants used SM as a useful avenue against misleading information. This reflects the professional responsibilities of pharmacists to educate the public in online activities, which is not different from professional traditional settings. WhatsApp, once again, has been proven as the popular medium for communication with patients. One participant used WhatsApp to remind a patient to take their medicine. However, another micromessaging platform, that is, Telegram, enabled one participant to attract a much larger number public members into a group of discussion as compared with WhatsApp.

The third theme describes public perception toward pharmacist involvement in SM. Participants felt that the public obtains the benefits from pharmacist activities in SM. In fact, a pharmacist is a truthful source of information for the public to ask in matters about medicines and health. As it was an online environment, people received responses from pharmacists faster and in real time. Nevertheless, convincing a patient to comply with pharmacist advices in an online environment is not an easy task. One participant mentioned that she was unable to prevent a patient from consuming herbal medicines that have not been proven safe and efficacious. As a result, the patient stopped her chemotherapy and eventually died.

The fourth theme shows that participants were confident and motivated to use SM for improving the health of the communities. However, a number of barriers may hamper pharmacist contributions using SM. Participants mentioned that online activities are burdensome, time consuming, affecting the privacy of the pharmacist, and fragile to lawsuit if the pharmacist has generated inappropriate responses. Furthermore, conversation in SM may jeopardize relationship with others, particularly elderly and respected individuals. In addition, several participants encountered difficulty to create good content with good appearance in SM. One participant mentioned that content and appearance determine the successful circulation (virality) of a message in SM. Unfortunately, she often felt unable to fulfill such expectation, leading to the termination of her message (Table 3).

\section{Discussion}

This study identified pharmacists' activities in SM and their contributions to the community health using SM. To the best of our knowledge, this is the first study observing pharmacists using SM in Indonesia. There are three key findings explored from this study related to the current use of SM by pharmacists, the opportunities for pharmacist contributions via SM, and the challenges of using SM.

The first key finding shows that SM has been used by pharmacists for supporting pharmacy practice. Apart from the fact that participants in this study mostly used SM for their personal and social life, there are some significant initiatives delivered by pharmacists to support practice using SM. For example, WhatsApp was used to debunk myths, misunderstanding, and misinformation about medications, treatments, and health issues. In the current era, information can be easily accessed by the lay public from the Internet and via SM. However, there is always a risk that such information might be misleading, a hoax, and potentially harmful to public health [19]. Using SM, pharmacists can fill this gap by providing valid and reliable professional information that the public can use as reference. A pharmacist's role against misleading information is particularly important in the setting of LMICs, including in Indonesia, because of poor health literacy and limited physical access to health care professionals [20]. Such role is actually not new to pharmacists in the conventional practice setting. However, the evidence showed positive feedback toward the efforts of pharmacists and health professionals in addressing false opinion and misinformation in an online environment [21].

The second key finding suggests that the use of SM provides an avenue to pharmacist role expansion and allows wider and larger number of public members to communicate with pharmacists compared with using conventional communication channels, e.g., face-to-face interaction. This study argued that physical interaction between a pharmacist and a patient is irreplaceable and fundamental to pharmacy services. Nevertheless, the use of SM offers alternatives for patients to interact with pharmacists in a professional manner without being limited by the distance and physical space. Several studies highlighted such opportunities, arguing that the contribution of pharmacists cannot be limited within the walls of the pharmacy [22], [23]. This study found that Telegram has been used by pharmacists to access more audience than any other SM applications. This can be considered a potential approach to communication in pharmacy.

The use of SM cannot be separated from the Internet. However, this study argued that pharmacists might contribute more in public health communication using SM than the traditional Internet format. Pharmacists have been using the Internet for professional purposes for years, mainly for accessing reliable information and communicating their business or services via websites and e-mail [24], [25]. By contrast, SM is an emerging platform of networking and communicating. Unlike the Internet in its traditional "passive" format, SM allows "active" interaction between users. In fact, a more intensive communication can be built on an SM platform 
by changing the privacy settings, which allow other users to become friends, followers, or subscribers. SM, therefore, seems to be a promising vehicle for the lay public to access a broad range of information, including medical and health information from the health care professionals as friends, followers, or subscribers. Many SM influencers and celebrities have used a similar method to advertise their business and products [26]. This can be an insight into alternative modes of interaction with patients and communities.

The third and the final key finding highlights that the use of SM is not without its challenges. Despite positive acceptance from the public and anecdotal evidence of pharmacist contributions in community health, being online in SM leads to a number of issues associated with time management, privacy, fears for inappropriate response, relationship with others, and lack of skills to create a viral message. A number of studies reported similar challenges reflecting pharmacist reluctance to continue to undertake professional activities when using SM [27], [28], [29]. Although SM quickly becomes a mainstream application nowadays, there is perhaps a pharmacist who resists this platform and becomes averse in SM. This might be the case for pharmacists in LMICs. For example, a pharmacist as an individual in Indonesia usually lives in a strong communal culture and bounded by strict relationships, such as respect for the elders and conflict avoidance [30]. This may affect pharmacist-patient relationship in a direct and open conversation such as in SM. Such challenge has not been explored in other publications, reflecting a novel finding generated from this study.

Several limitations need to be noticed from this study. SM in the FGD is mostly referred to social networking and sharing content platform. There are numerous types of SM, and such restriction may not portray the broader horizon of other SM types, such as LinkedIn and Google+, which are commonly used for professional business. Other limitations include the inclusion of some pharmacist SM influencers into the FGD, which may not represent the overall picture and habits of pharmacists in the SM as these persons really devote their time to exist in SM.

\section{Conclusions}

SM has become a venue for pharmacists to improve health of the people. Several unique features in SM may facilitate pharmacist contributions; however, whether pharmacists continue to undertake such initiative cannot be guaranteed.

\section{Acknowledgments}

This study has been presented at the 2019 International Joint Symposium of the 8th Asia Pacific Pharmacy 8-9 October 2019, at Universitas Airlangga, Surabaya, Indonesia.

\section{Funding}

This research received funding from Universitas Airlangga Indonesia under the Mandate Research Scheme Grant 2019, Funder Id: http:/ /dx.doi.org/10.13039/501100008463.

Author contributions: All authors have accepted responsibility for the entire content of this manuscript and approved its submission.

Competing interests: The authors state no conflict of interest.

Informed consent: Informed consent was obtained from all individuals included in this study.

Ethical approval: Research involving human subjects complied with all relevant national regulations and institutional policies, was in accordance with the tenets of the Declaration of Helsinki (as revised in 2013), and has been approved by the Board of Social and Political Studies of East Java (No. 070/6700/209.4/2018) and the Indonesian Pharmacist Association (No. B2.106/PP.IAI/1822/VIII/2019). 


\section{References}

[1] Kemp S. Global Digital 2019 reports. New York: We Are Social Ltd, 2019 [updated 30 ]anuary 2019; cited 2019. Available at: https://wearesocial.com/global-digital-report-2019.

[2] Rathbone AP, Norris R, Parker P, Lindsley A, Robinson A, Baqir W, et al. Exploring the use of WhatsApp in out-of-hours pharmacy services: a multi-site qualitative study. Res Soc Admin Pharm 2019.

[3] Hindman FM, Bukowitz AE, Reed BN, Mattingly T]. No filter: a characterization of \#pharmacist posts on Instagram. ] Am Pharm Assoc 2017:57:318-25.

[4] Westerfield B, Cain ]. Why and how community pharmacies should better use Facebook. ] Am Pharm Assoc 2019;59:S30-4.

[5] Ventola CL. Social media and health care professionals: benefits, risks, and best practices. P T 2014;39:491-520.

[6] Ceorge DR, Rovniak LS, Kraschnewski ]L. Dangers and opportunities for social media in medicine. Clin Obstet Gynecol 2013;56:453-62.

[7] Skelley ], Hughes P, Elmore L. Social media and unprofessional pharmacist conduct: a cross-sectional survey of boards of pharmacy. Innov Pharm 2013;4:1-11.

[8] Alkhateeb FM, Clauson KA, Latif DA. Pharmacist use of social media. Int ] Pharm Pract 2011;19:140-2.

[9] Crindrod K, Forgione A, Tsuyuki RT, Gavura S, Giustini D. Pharmacy 2.0: a scoping review of social media use in pharmacy. Res Soc Admin Pharm 2014;10:256-70.

[10] Hajar Z, Clauson KA, Jacobs R]. Analysis of pharmacists' use of Twitter. Am ] Health Syst Pharm 2014;71:615-9.

[11] Barry AR, Pearson G]. Professional use of social media by pharmacists. Can ] Hosp Pharm 2015;68:22-7.

[12] Poushter ], Bishop C, Chwe H. Social media use continues to rise in developing countries but plateaus across developed ones. Pew Research Center 2018;22.

[13] Kemp S. Digital in Southeast Asia in 2017. New York: We Are Social Ltd, 2017 [updated 16 February 2017; cited 2019. Available at: https://wearesocial.com/special-reports/digital-southeast-asia-2017.

[14] Indonesia Internet Service Provider Association. Laporan Survei Penetrasi dan Profil Perilaku Pengguna Internet Indonesia (The survey report of penetration and profile of Internet users in Indonesia 2018). Jakarta: Indonesia Internet Service Provider Association, 2018.

[15] Statistics Indonesia. Population of Indonesia. Jakarta: Statistics Indonesia, 2019 Available at: https://www.bps.go.id/subject/12/kependudukan.html\#subjekViewTab3.

[16] Benetoli A, Chen TF, Aslani P. The use of social media in pharmacy practice and education. Res Soc Admin Pharm 2015;11:1-46.

[17] Hermansyah A, Sainsbury E, Krass I. Investigating the impact of the universal healthcare coverage programme on community pharmacy practice. Health Soc Care Community 2018;26:e249-60.

[18] Athiyah U, Setiawan CD, Nugraheni G, Zairina E, Utami W, Hermansyah A. Assessment of pharmacists' knowledge, attitude and practice in chain community pharmacies towards their current function and performance in Indonesia. Pharm Pract (Granada) 2019;17:1518.

[19] Del Vicario M, Bessi A, Zollo F, Petroni F, Scala A, Caldarelli G, et al. The spreading of misinformation online. Proc Natl Acad Sci 2016;113:554.

[20] Hermansyah A, Sainsbury E, Krass I. Multiple policy approaches in improving community pharmacy practice: the case in Indonesia. BMC Health Serv Res 2018;18:449.

[21] Chou W-YS, Oh A, Klein WMP. Addressing health-related misinformation on social media. J Am Med Assoc 2018;320:2417-8.

[22] Cain ], Romanelli F, Fox B. Pharmacy, social media, and health: opportunity for impact. ] Am Pharm Assoc 2010;50:745-51.

[23] Crilly P, Hassanali W, Khanna G, Matharu K, Patel D, Patel D, et al. Community pharmacist perceptions of their role and the use of social media and mobile health applications as tools in public health. Res Soc Admin Pharm 2019;15:23-30.

[24] Wagner ML, Alonso ], Mehlhorn A]. Comparison of Internet and community pharmacies. Ann Pharmacother 2001;35:116-9.

[25] Peterson-Clark G, Aslani P, Williams KA. Pharmacists' online information literacy: an assessment of their use of Internet-based medicines information. Health Inf Libr ] 2010;27:208-16.

[26] Khamis S, Ang L, Welling R. Self-branding, 'micro-celebrity' and the rise of social media influencers. Celebr Stud 2017;8:191-208.

[27] Moorhead SA, Hazlett DE, Harrison L, Carroll JK, Irwin A, Hoving C. A new dimension of health care: systematic review of the uses, benefits, and limitations of social media for health communication. J Med Internet Res 2013;15:e85.

[28] Shcherbakova N, Shepherd M. Community pharmacists, Internet and social media: an empirical investigation. Res Soc Admin Pharm 2014;10:e75-85.

[29] Benetoli A, Chen TF, Schaefer M, Chaar B, Aslani P. Do pharmacists use social media for patient care? Int ] Clin Pharm 2017;39:364-72.

[30] Hermansyah A, Sukorini AI, Setiawan CD, Priyandani Y. The conflicts between professional and non professional work of community pharmacists in Indonesia. Pharm Pract (Granada). 2012;10:33-9. 